\title{
Padrões de Relacionamentos entre Grupos de Pesquisa e o Setor Produtivo do Brasil: uma Análise Multivariada dos Tipos de Relacionamento por área de Conhecimento
}

\section{Patterns of Relationship between Research Groups and Productive Sector in Brazil: an Multivariate Analysis of Relationship Types by Fields of Knowledges}

\author{
Lucas Teixeira Araújo* \\ Jorge Nogueira de Paiva Britto**
}

\begin{abstract}
Resumo: O artigo tem como objetivo realizar uma análise da interação entre universidade e empresa no sistema nacional de inovação brasileiro pela ótica dos grupos de pesquisa, separado em áreas do conhecimento. Para tanto, são definidos indicadores a partir da técnica de componente principal com o objetivo de analisar as semelhanças e diferenças entre as áreas de conhecimento dos tipos de interação que cubram as particularidades do sistema nacional de inovação brasileiro. A análise realizada demonstra que os tipos de interação são muito diversos para os grupos de pesquisa do Brasil e variam de acordo com a área de conhecimento na qual eles estão inseridos. Os resultados demonstram que a interação no Brasil assume várias formas e é heterogênea nas diferentes ciências. Esse ponto serve para qualificar o sistema de ciência e tecnologia nacional perante suas particularidades, além de guiar políticas que gerem ciclos virtuosos.
\end{abstract}

Palavras-chave: Interação universidade/empresa. Sistema de ciência e tecnologia. Sistema nacional de inovação.

\begin{abstract}
This article aims to develop an analysis about universities-firms interaction in the Brazilian national system of innovation from the view of academic research group, disaggregated in different in knowledge areas. Some indexes are defined by a principal component analysis (PCA), comprising the interactions types in order to identify similarities and differences among the research areas which covers particularities of the Brazilian national system of innovation. The analysis shows that the types of interactions are very different to the research groups in Brazil and vary according to the area of knowledge in which they are inserted. The result shows that interaction in Brazil assumes many types and is also heterogeneous to different sciences. This point helps to qualify national system of science and technology besides particularities and guides policies that sire virtuous cycles.
\end{abstract}

Doutorando pelo Programa de Pós-Graduação em Economia (PPGE) da Universidade Federal Fluminense (UFF). Bolsista de doutorado CAPES. E-mail: lucast a@ymail.com

* $\quad$ Professor do Programa de Pós-Graduação em Economia da Univiversidade Federal Fluminense (PPGE-UFF). E-mail: britto.jorge@gmail.com 
Keywords: Universities/firms interaction. National system of science and technology. National system of innovation.

JEL Classification: $\mathrm{O} 31 ; \mathrm{O} 32 ; \mathrm{O} 33$.

\section{Introdução}

O artigo aborda a temática a respeito da interação entre universidades e empresas a partir de uma perspectiva neo-schumpeteriana. Esse tema se torna importante à medida que os economistas buscam compreender os fluxos de conhecimento que geram desenvolvimento econômico, concebidos como um elemento crítico dos sistemas nacionais de inovação. Os trabalhos sobre interação entre universidades e empresas se intensificaram a partir do início da década de 1990 (KLEVORICK et al., 1995), o que se deu pela constatação de que as universidades teriam particular importância no que diz respeito à formação de capital humano. Cohen et al. (2002) desenvolvem uma metodologia que buscava identificar os padrões de interação e como a universidade contribuía em outros campos diferentes da simples formação de recursos humanos. Schartinger et al. (2001) adotam uma metodologia que utiliza elementos dos dois surveys americanos para um estudo aplicado à Áustria. Seguindo essa linha, vários outros surveys surgiram, destacando-se os trabalhos aplicados para a Holanda (TIJSSEN, 2006), a Suíça (ARVANITS et al., 2006), o México (FUENTES; DUTRÉNIT, 2012), Argentina (ARZA, 2010) e Brasil (SUZIGAN, et al., 2011).

O presente artigo busca caracterizar padrões de relacionamento dos grupos de pesquisa em termos dos tipos de interação com empresas, organizados por área de conhecimento. Essa problemática é vista como um elemento importante para caracterizar o grau de sofisticação de um sistema nacional de inovação. Presume-se que algumas formas de relacionamento, como aquelas relacionadas ao PED conjunto, sejam mais virtuosas para a geração de tecnologia que outras, como a atividade de consultoria. A análise é desenvolvida em seis seções, além dessa introdução. A segunda seção apresenta o referencial teórico que fundamenta a análise desenvolvida. A terceira seção é dedicada à caracterização da base de dados e a quarta seção realiza a caracterização por estatísticas descritivas dos grupos de pesquisa estudados. A quinta seção descreve a metodologia utilizada de análise fatorial pelos métodos de componente principal e análise de clusters. A sexta seção apresenta os resultados encontrados pelo método descrito na seção anterior. Por fim, são realizadas as considerações finais. 


\section{Referencial Teórico}

Freeman e Soete $(2008)^{1}$ desenvolvem o conceito de sistema nacional de inovação a partir de uma perspectiva histórica, com base na teoria de List (1983). A Alemanha havia desenvolvido um sistema diferente do inglês no fim do século XIX, constituindo um forte sistema de treinamento e educação para a sua população, além de ter presenciado o surgimento dos grandes laboratórios de pesquisa das companhias, principalmente no setor químico. Essas especificidades germânicas fizeram com que o país superasse a Inglaterra em muitos indicadores econômicos já no final do século XIX. Outro país que se destacou no final do século XIX e tinha optado por uma estratégia peculiar foi os Estados Unidos. Esse baseou seu desenvolvimento na abundância de recursos naturais além de uma maior concentração em atividades intensivas em capital e uma escala de produção maior que a bretã. Freeman e Soete (2008) comparam também as trajetórias dos japoneses com a União Soviética e dos países do Leste Asiático com os latino-americanos. Para os autores, tanto os japoneses quanto os países do Leste Asiático se saíram melhores em suas mudanças institucionais que levaram ao desenvolvimento econômico.

Outro estudo fundamental foi realizado por Nelson (1993), que caracteriza o sistema nacional de inovação como o conjunto das instituições que levariam ao desempenho inovativo das firmas de um determinado país. $\mathrm{O}$ autor edita um trabalho comparativo do desenvolvimento econômico de 13 países, evidenciando a evolução institucional de cada um deles. Também é feita uma introdução conceitual na qual buscam uma definição concisa do termo. Nessa abordagem, o agente mais importante seriam as firmas e o agente secundário seriam as universidades, os institutos públicos de pesquisa e os governos. Esse grupo secundário daria apoio às firmas com o intuito de levá-las a uma posição de destaque e competitividade no mercado mundial. Lundvall (2005) vê essa definição como estreita e propõe um conceito mais abrangente. Entretanto, isso não tira o brilhantismo do trabalho de Nelson (1993), que nos possibilita encontrar as semelhanças e diferenças de cada sistema nacional de inovação.

Lundvall (2005) desenvolve uma abordagem particular do conceito de sistemas nacionais de inovação. Nessa visão, atribui mais atenção aos processos de interação, transmissão de conhecimento e aprendizado. Esses processos passam a ter importância significativa para o desenvolvimento econômico de um país no que o autor chamou de "economia do conhecimento". Assim, os processos inovativos estariam fortemente correlacionados com a existência de relações entre as organizações inovadoras de fato, firmas, e as organizações difusoras de qualidades técnicas e científicas como universidades e institutos

$1 \quad$ O texto utilizado aqui corresponde à tradução em português do trabalho "The 'National system of innovation' in historical perspective”, publicado em 1995 no Cambridge Journal of Econiomics. 
públicos de pesquisa (LUNDVALL, 1992). Os países teriam modos distintos de organizar essas interações, pois se diferenciam por suas culturas, normas, leis e regras peculiares (JONHSON, 1992). Cooke et al. (1998) propõem uma divisão segundo a qual se deveria tratar como instituição apenas aquelas definidas na visão vebleniana e, governos, firmas, universidades e institutos de pesquisa deveriam ser entendidos como organizações. As instituições seriam as regras do jogo enquanto as organizações seriam os jogadores, sendo que essas duas partes realizam as interações (COOKE et al., 1998).

Os estudos de sistemas de inovação não se esgotam nessas análises e uma série de determinações secundárias do conceito apareceu na literatura. Dentre essas, pode-se identificar aquelas referidas aos conceitos de sistemas regionais de inovação (COOKE et al., 1998), sistemas setoriais de inovação (MALERBA, 2002), sistemas de cidades inovadoras (JOHNSON, 2008) e sistemas nacionais de inovação imaturos (ALBUQUERQUE, 1999; BERNARDES; ALBUQUERQUE, 2003). $\mathrm{Na}$ análise desenvolvida a seguir, o último desses será considerado. Albuquerque (1999) definiu essa estrutura da seguinte forma, com base no trabalho de Freeman e Soete (2008):

They share with Latin American economies some characteristics described by Freeman (1995): the existence of science infrastructure (university research institutes, and governments agencies); weak commitment of business firms to innovative investments; presence of education skills, but with problems and serious flaws (ALBUQUERQUE, 1999, p. 37).

No trabalho de Bernardes e Albuquerque (2003), os autores constroem um modelo que relaciona o número de patentes ao número de artigos produzidos por um país com o intuito de definir um sistema imaturo. O resultado demonstra uma quebra estrutural que representa a diferença entre países maduros e imaturos, sendo o Brasil localizado dentro dos países imaturos. Isso sugere que o conhecimento gerado no país é insuficiente para criar uma dinâmica inovadora. Essa característica pode ser relacionada com problemas históricos do nosso processo de industrialização no que diz respeito à absorção tecnológica (BERNARDES; ALBUQUERQUE, 2003). Nos países com um sistema nacional de inovação imaturo, o processo de interação universidade-empresa é debilitado pelo enfraquecimento das bases do sistema nacional de inovação, bem como em função do baixo nível de PED interno realizado pelas empresas (SUTZ, 2000). O trabalho de Arocena e Sutz (2003) diz que as particularidades dos sistemas nacionais de inovação dos países latino-americanos levariam a tipos de interação tradicionais e de pouca capacidade de trocas tecnológicas. Esse ponto, porém, é questionado nos trabalhos de Rapini (2007) e Suzigan et al. (2011), os quais percebem uma complexidade e riqueza bem maiores nas interações brasileiras. 
A partir desse contexto, é reforçada a relevância da temática da intensidade e amplitude da interação universidade-empresa como um elemento fundamental para a constituição dos sistemas nacionais de inovação. A importância da contribuição do conhecimento científico para a viabilização de processos inovativos coloca o papel estratégico desempenhado pelas universidades e institutos de pesquisa na medida em que os mesmos constituem uma fonte primordial de geração desse conhecimento. Essas instituições desempenham um papel crescentemente importante, seja como fonte de conhecimento geral ou específico, seja na formação de profissionais aptos ao envolvimento com atividades inovativas no meio empresarial. Apesar do argumento de que a comunidade acadêmica e o setor empresarial operam como instâncias de geração de conhecimentos que se movem segundo lógicas distintas, as quais se refletiriam nos respectivos quadros de referência e nos padrões de comportamento dos agentes inseridos em cada contexto, observa-se um movimento geral de aproximação entre essas instâncias com a consolidação de uma economia crescentemente "baseada no conhecimento" (LASTRES et al., 2002). Sendo assim, a esfera acadêmica constitui um importante agente motor do desenvolvimento, oferecendo um suporte fundamental à difusão do progresso técnico e à construção de capacitações produtivas e inovativas nos planos nacional e regional.

No âmbito de uma economia crescentemente "baseada no conhecimento", é possível destacar uma dinâmica mais geral marcada por forças indutoras de um aprofundamento das interações entre o mundo acadêmico e a esfera industrial. Por um lado, esse aprofundamento reflete mudanças que vêm se processando no sistema de valores que orientam as ações de agentes inseridos na comunidade acadêmica, particularmente no sentido do fortalecimento de uma visão "mission oriented" (GIBBONS et al., 1994), responsável pela geração de incentivos à realização de investigações em linhas de PEBD associadas a oportunidades atrativas de aplicações técnico-econômicas. Por outro lado, também se observa uma tendência ao fortalecimento do caráter interdisciplinar do conhecimento, não apenas no tocante a disciplinas estritamente científicas, como também no plano mais diretamente material das disciplinas de base tecnológica. Como consequência desses processos, verifica-se a consolidação de arranjos institucionais integrando as duas instâncias, a partir dos quais estrutura-se um sistema de incentivos adequado ao aprofundamento da interação, os quais assumem múltiplos formatos, tais como joint-ventures, incubadoras de empresas, parques tecnológicos, consórcios de PED, centros de transferência de tecnologia, centros de pesquisa cooperativa, instituições-ponte dedicadas ao gerenciamento de contratos de pesquisa, spin-offs de empresas de base tecnológica e alianças informais entre indústria, governo e universidades. 
A interação universidade-indústria tem sido enfatizada por uma vasta literatura no campo da economia da inovação, a qual ressalta a importância dos circuitos de retroalimentação positiva entre essas duas dimensões, característico dos sistemas de inovação consolidados dos países desenvolvidos. Nesses sistemas, é comum que as universidades e institutos de pesquisa produzam conhecimentos absorvidos por empresas e pelo setor produtivo, conforme comprovam estudos realizados por Klevorick et al. (1995), Narin et al. (1997) e Cohen et al. (2002). Por outro lado, as empresas acumulam conhecimento tecnológico que fornece questões para a elaboração científica, conforme descrito por Rosenberg (1982). Como reflexo desse processo, consolidam-se fluxos virtuosos bidirecionais entre essas instâncias, conforme discutido nas análises de Brascomb et al. (1999) e de Mowery et al. (2004).

A partir dos diversos trabalhos realizados nessa linha, é possível destacar algumas conclusões importantes. Em especial, podem ser observadas algumas características das universidades envolvidas nas interações, como o fato de os grupos de pesquisa usualmente se beneficiarem pela aquisição de recursos financeiros na criação de novas oportunidades tecnológicas e na publicação de artigos (PERKMANN; WALSH, 2008). Além disso, é possível observar alguns resultados no que diz respeito às características dos pesquisadores. Aqueles que pertencem a institutos públicos de pesquisas têm mais probabilidade de estarem interagindo com empresas que aqueles empregados em universidades (BOARDMAN; PONOMARIOV, 2009). Fatores como gênero, idade e experiência também exercem influência nas relações com empresas (BEKKERS; BODAS-FREITAS, 2008), sendo que homens interagem mais. A experiência, contada por frequência de interações, também atua de forma positiva e a idade atua como uma espécie de ' $U$ ' invertido. A disponibilidade de recursos oferecida ao pesquisador pelo seu departamento e a qualidade das pesquisas concluídas também são fatores que afetam as interações (SCHARTINGER et al., 2002). Por fim, nota-se que a interação gera tanto custos indesejados quanto resultados vantajosos para as universidades, sendo necessário um sistema de governança específico (CUMMINGS; KIESLER, 2007).

Quanto às firmas, observa-se que elas estão interessadas em identificar mão de obra potencial além de capacitações científicas que podem ser utilizadas como aplicações para o mercado (ARVANITS et al., 2006). Vários trabalhos buscaram encontrar características das firmas que fazem aumentar as interações, como o tamanho (PÓVOA; MONSUETO, 2011), se a firma é parte de uma grande corporação (FUENTES; DUTRÉNIT, 2012), o setor em que elas se encontram (BRITTO; OLIVEIRA, 2011; TIJSSEN, 2006), a intensidade tecnológica (PINHO, 2011) e o fato de uma empresa ser nacional ou multinacional (SILVA NETO et al., 2011). Existem ainda estudos que observam se a proximidade geográfica influencia na 
interação das firmas com os grupos de pesquisa (COSTA et al., 2011; GARCIA et al., 2011).

Quanto à transmissão de conhecimento, pode-se ver que tanto trabalhos iniciais (KLEVORICK et al., 1994) quanto os atuais (BEKKERS; BODAS-FREITAS, 2008) colocam a mobilidade de recursos humanos entre universidades e firmas como uma das formas mais importantes. A publicação de resultados de PED por artigos acadêmicos também é uma forte fonte de transmissão de tecnologia, porém menos comum, dado que as firmas especificam tais termos em contratos (PERKMANN; WALSH, 2008. É possível observar no trabalho de Fuentes e Dutrénit (2012) que os canais de interação são separados em certos grupos, dependendo do grau de formalização, do grau de interação, da direção dos fluxos de conhecimento e da natureza dos resultados aplicados.

A partir dessa perspectiva, Suzigan e Albuquerque (2009) e Rapini (2007) identificam, com base na literatura especializada, algumas funções fundamentais da universidade: (1) formação de pessoal em geral; (2) formação de pessoal capacitado para fundar novas empresas, especialmente em novas áreas tecnológicas ("spin-offs"); (3) fonte de conhecimento de caráter mais geral necessários para as atividades de pesquisa básica e fonte de conhecimento especializado relacionado à área tecnológica da firma; (4) geração de conhecimento na forma de "spillovers" (utilizados por empresas e outros agentes com capacidade de absorção previamente construída); (5) estabelecimento de interação com firmas estabelecidas, favorecendo processos inovativos; (6) estabelecimento de canal para absorção de conhecimento gerado nos centros mais avançados. No âmbito específico dos países em desenvolvimento, destaca-se o papel da ciência na contribuição para o processo de catching up, na medida em que a infraestrutura científica atua como um "instrumento de focalização" e como uma "antena" para identificar oportunidades tecnológicas, permitindo vincular o país aos fluxos científicos e tecnológicos internacionais. Esse fato serve de apoio ao desenvolvimento industrial e atua como fonte para soluções criativas que dificilmente seriam obtidas fora do país (como, por exemplo, no caso de vacinas contra doenças tropicais, ou mesmo a 'tropicalização' de veículos para o mercado brasileiro).

No caso latino-americano, em função do baixo nível de PESD interno realizado pelas empresas locais, Arocena e Sutz (2003) encontram evidências de que as articulações universidade-empresa no continente tendem a ficar circunscritas à prestação de serviços rotineiros e a atividades de consultoria técnica, raramente envolvendo atividades de pesquisa de caráter mais experimental. Entretanto, Rapini (2007) e Rapini et al. (2013) observam na região uma mudança de postura das universidades e instituições de pesquisa no sentido de acelerar investigações orientadas para busca de avanços que tenham uma maior relevância para a socie- 
dade com pesquisas mais densas e que possibilitem uma comercialização efetiva dos resultados gerados.

Muitos estudos sobre o caso brasileiro trabalham com a noção de que o país dispõe de um sistema nacional de inovação imaturo. Nesse sentido, observa-se que o país tem um grande número de instituições de pesquisa e ensino, porém não consegue constituir uma pesquisa densa e gerar a quantidade de engenheiros suficientes para tal atividade (SUZIGAN; ALBUQUERQUE, 2008). Pode-se perceber ainda que as universidades são utilizadas como o próprio departamento de PEBD das empresas (FRANCO et al., 2010). Entretanto, o país é conhecido historicamente por gerar progressos científicos relevantes em determinadas áreas. Dentre esses campos, é possível destacar a aeronáutica, imunologia, agropecuária, mineração e geociências (SUZIGAN; ALBUQUERQUE, 2008).

Esse quadro reforça a importância de avaliar-se o padrão de interação universidade-empresa em um país com um sistema de inovação que, grosso modo, pode ser caracterizado como "imaturo" (ALBUQUERQUE, 1999). Segundo análises anteriores sobre essa temática (RAPINI, 2004; SILVA, 2003; BERNARDES; ALBUQUERQUE, 2003), há indícios de que, dado o estágio de desenvolvimento do país e o estágio ainda imaturo de construção do sistema nacional de inovação, as conexões estabelecidas entre a dimensão científica e a dimensão tecnológica são apenas parciais no caso brasileiro. Desse modo, fluxos bidirecionais e mutuamente dinâmicos parecem estar limitados a alguns setores e a campos específicos do conhecimento. Além disso, há também indícios de que, em vários campos, prevalecem fluxos unidirecionais originados principalmente das universidades - em função da maior participação relativa do Brasil na produção científica mundial vis-à-vis a sua participação na produção tecnológica (ALBUQUERQUE, 1999). Por outro lado, face às evidências que apontam para o caráter limitado dessas interações no caso brasileiro (RAPINI, 2004; SILVA, 2003; BERNARDES; ALBUQUERQUE, 2003; RAPINI et al., 2013), torna-se particularmente importante quais as especificidades desse padrão de interação em diferentes campos do conhecimento.

\section{Base de Dados}

O artigo discute a interação univerisidade-empresa a partir de um recorte por diferentes campos do conhecimento. A base de dados utilizada integra a pesquisa denominada "A program of study of the processes involved in technological and economic catch up", organizada pelo professor Richard Nelson da Universidade de Columbia (SUZIGAN et al., 2011). Tal pesquisa consiste em duas modalidades de questionários direcionadas para as empresas e universidade e instituto de pesquisa. Os dados foram coletados entre 2007 e 2010. 
$\mathrm{Na}$ análise realizada, foi utilizado apenas o questionário aplicado a universidades e instituições de pesquisa. Participaram desse estudo todos os grupos de pesquisa que disseram ter algum tipo de interação com empresas no Censo de Grupos de Pesquisa de 2004. As informações acerca das interações e cooperações entre as universidades e as empresas são do ano de 2008 e o questionário busca compreender e avaliar todo o processo de interação entre os agentes em questão. A estratégia de captação de resposta foi realizada por correio eletrônico, acompanhamento telefônico ou acompanhamento presencial. No total, foram contatados 2.151 grupos de pesquisa e obteve-se 1.005 respostas, o que gerou uma taxa de $46,7 \%$. Depois de uma limpeza para os dados que aqui serão trabalhados, restaram 889 grupos, o que gera uma taxa de representatividade de $41,3 \%$ do universo. Entretanto, considerando apenas os grupos das grandes áreas do conhecimento pré-selecionadas, tem-se uma participação de $47,26 \%$ do total. ${ }^{2}$

O percentual de resposta é bom para todas as áreas de conhecimento, tanto grandes áreas como áreas específicas. O percentual das grandes áreas de conhecimento são, respectivamente, Engenharia (50,63\%), Ciências Biológicas (50,45\%), Ciências Agrárias (45,16\%), Ciências Exatas e da Terra (44,70\%) e Ciências da Saúde $(42,80 \%)$. É interessante observar que os percentuais de resposta das áreas do conhecimento não são muito diferentes do observado para o total. Por fim, cabe ressaltar que para Engenharia Biomédica, o Survey Brasil conseguiu captar 100\% dos grupos que disseram ter alguma relação com empresas no censo do CNPq, enquanto que para Medicina foi encontrada a menor taxa de resposta, 39,29\%.

A base de dados contém uma série de informações, tais como tamanho do grupo de pesquisa, localização geográfica, universidade ou instituto ao qual pertence o grupo, escolaridade dos membros do grupo, dentre outras. Na próxima seção, faz-se uma breve descrição dos dados a partir de algumas informações descritivas e em seguida será aplicado o método de multivariável de componente principal.

\section{Características de Grupos de Pesquisa Investigados e Tipos de Relaciona- mentos com o Setor Produtivo}

Os grupos de pesquisa foram divididos de acordo com suas áreas de pesquisa declaradas pelos seus pesquisadores chefes. Para que fosse possível trabalhar com todos os dados, algumas áreas do conhecimento tiveram que ser agregadas devido ao baixo número de observações. Assim, recursos ambientais e engenharias afins correspondem a áreas do conhecimento de recursos florestais e Engenharia Florestal e recursos pesqueiros e engenharias de pesca; as áreas de bioquímica e biofísica foram agrupadas; foram reunidos os grupos de Biologia geral, botânica,

2 O trabalho não considerou as áreas de Ciências Humanas, Ciências Humanas Aplicadas e Linguística. 
morfologia e zoologia; os grupos das áreas imunologia, microbiologia, parasitologia, farmacologia e fisiologia foram alocados em um mesmo conjunto; Educação física, Enfermagem, Fisioterapia e Terapia Ocupacional, Fonoaudiologia e Nutrição também integram um mesmo conjunto; foram acrescentados os grupos de Matemática e de probabilidade junto às Ciências da Computação; adicionaram-se dois grupos de Engenharia de Transportes à Engenharia Civil; e por fim um grupo de Engenharia Naval foi incorporado aos grupos de Engenharia Mecânica. Com base nessa divisão, foi gerada a Tabela 1 .

Pode observar-se que o número médio de pesquisadores dos grupos da base é de 10,52. Desses, 4,62 têm doutorado, o que dá uma proporção de 43,85\% dos pesquisadores. Dentre as grandes ciências, aquela que tem uma média de pesquisadores maior por grupo é a ciências agrárias. Uma explicação para isso pode ser dada pela força da Embrapa e outros institutos estaduais de pesquisa, como a Epamig de Minas Gerais e a Epagri de Santa Catarina. Essas instituições têm uma infraestrutura bem desenvolvida e amparada por governos estaduais e federais que garantiu um forte desenvolvimento agrário brasileiro (MAZZOLENI; NELSON, 2007). Os grupos desses institutos de pesquisa governamentais nas ciências agrárias são 26 (13\% do total da grande área) e têm uma média de 17,6 pesquisadores. Dentre as áreas de conhecimento específicas, os grupos com menos pesquisadores são engenharia nuclear e bioquímica e biofísica, que são ciências com certa dificuldade de encontrar pessoal capacitado. Entretanto, grupos das áreas de engenharia de produção, saúde coletiva e biologia geral, botânica, morfologia e zoologia também apresentam números baixos de pesquisadores. 


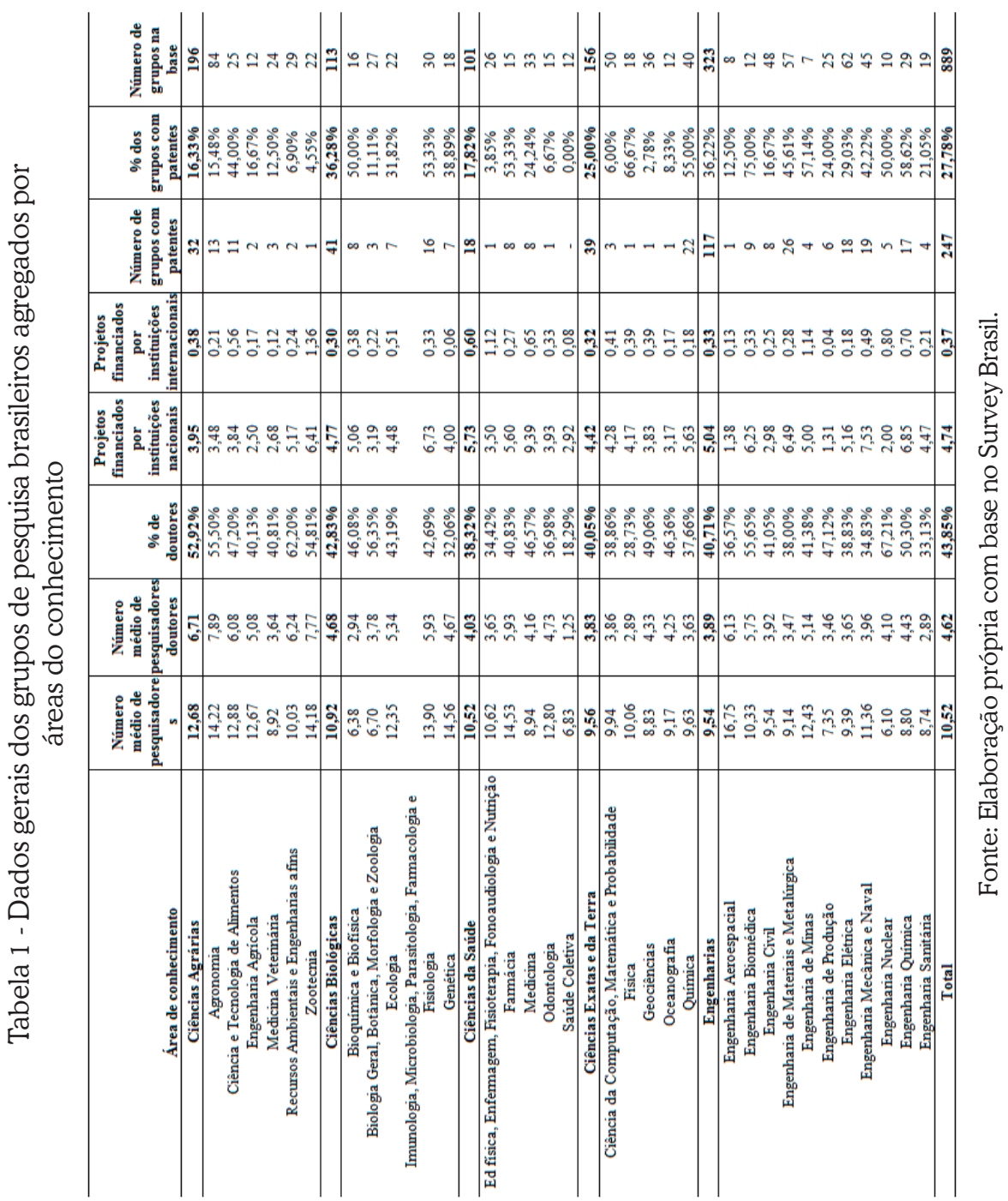


Quanto ao percentual de pesquisadores com doutorado, o grupo de ciências agrárias se destaca novamente. Esse é o único grupo em que o percentual é maior que 50\%, o que em boa parte se deve aos percentuais de doutores em Agronomia (55,50\%), recursos ambientais e engenharias afins (62,20\%) e zootecnia (54,81\%). Algumas outras ciências também apresentam alto percentual como Engenharia Nuclear (67,21\%), Biologia geral, botânica, morfologia e zoologia (56,35\%) e Engenharia Biomédica (55,65\%). A ciência que apresenta o menor percentual é a saúde coletiva (18,29\%). Entretanto, o que chama a atenção é o baixo percentual encontrado para Genética (32,06\%), ciência que se espera ser dominada por um tipo de conhecimento mais especializado e tem certa tradição de pesquisa no Brasil.

As ciências da saúde apresentam 5,73 projetos financiados, em média, por instituições nacionais, sendo o maior valor médio para essa categoria. A mesma área do conhecimento aparece como aquela que recebe maior número médio de projetos financiados por instituições do exterior, 0,60 por grupo. Esses dados são bastante reforçados pelos grupos de Medicina que apresentam uma média de 9,39 projetos financiados por instituições nacionais e por Educação Física, Enfermagem, Fisioterapia, Fonoaudiologia e Nutrição, com 1,12 projetos financiados por instituições internacionais. Os valores totais para o Brasil são de 4,74 e 0,37 respectivamente.

A grande área do conhecimento com maior número bruto de patentes são as engenharias, entretanto cabe ressaltar que essa é a ciência de maior representação na amostra. Em percentual, os grupos de ciência biológica são os que destacam com mais de uma patente para cada três grupos. Isso, inclusive, é um fato para explicar o motivo dessa área se destacar na atração de financiamento de instituições estrangeiras. Dentre as ciências específicas do conhecimento, aquelas que apresentam pelo menos a metade dos grupos com pedidos de patentes são Engenharia Biomédica (75,00\%), Física (66,67\%), Engenharia Química (58,62\%), Engenharia de Minas (57,14\%), Química (55,00\%), imunologia, microbiologia, parasitologia, farmacologia e fisiologia (53,33\%), Farmácia (53,33\%), bioquímica e biofísica (50,00\%) e Engenharia Nuclear (50,00\%). Esse conjunto de áreas, quando contraposto com aquele que tem poucos grupos com pedidos de patentes, nos dá um indício da diferença das relações entre as universidades e o setor privado. Essas áreas terão uma tendência muito maior de trocas bilaterais de tecnologia e de projetos de joint research (ARZA, 2010), enquanto os grupos de áreas como saúde coletiva $(0,00 \%$ de patente por grupos) terá uma tendência maior para desenvolvimento de projetos de troca unilateral de conhecimento, como congressos, seminários e cursos e treinamentos.

Neste trabalho, serão utilizadas as respostas da questão 1 da seção II, que contempla os tipos de relacionamentos da interação de grupos de pesquisa com 
empresas $^{3}$ da pesquisa acima apresentada (SUZIGAN et al., 2011). O Quadro 1 demonstra que essa dimensão pode ser abordada a partir da diferenciação entre duas alternativas principais de tipos de relacionamentos - prestação de serviços e atividades de PEB - que se desdobram em onze possíveis tipos de relacionamentos. Nessas questões, o entrevistado teve que dizer se as considerava sem importância (1), pouco importante (2), moderadamente importante (3) e muito importante (4). Assim, deve-se fazer a ressalva que os dados aqui trabalhados são subjetivos e transmitem as percepções dos chefes dos grupos de pesquisa.

Quadro 1 - Indicadores de tipos de interação universidade-empresa

\begin{tabular}{|c|c|c|}
\hline Questão & Tipos principais & Alternativas avaliadas \\
\hline & $\begin{array}{l}\text { 1. Prestação de } \\
\text { serviços } \\
\text { (indicador 1) }\end{array}$ & $\begin{array}{c}\text { Q1.1. Testes para padronização /ativi- } \\
\text { dades de certificação da qualidade } \\
\text { Q1.2. Avaliações técnicas, estudos } \\
\text { de viabilidade, gerenciamento de } \\
\text { projetos } \\
\text { Q1.3. Serviços de engenharia } \\
\text { Q1.4. Consultoria } \\
\text { Q1.5. Treinamento e cursos } \\
\text { Q1.6. Intercâmbio nas empresas }\end{array}$ \\
\hline $\begin{array}{l}\text { Questão 1: } \\
\text { Tipos de } \\
\text { relacionamento }\end{array}$ & $\begin{array}{c}\text { 2. PED } \\
\text { (indicador 2) }\end{array}$ & $\begin{array}{l}\text { Q1.7. Transferência de tecnologia } \\
\text { (licenciamento) } \\
\text { Q1.8. Projetos de PED em colabo- } \\
\text { ração com a empresa, com resultados } \\
\text { de uso imediato } \\
\text { Q1.9. Projetos de PED em colabo- } \\
\text { ração com empresas, sem resultados } \\
\text { de uso imediato } \\
\text { Q1.10. Projetos de PEDD complemen- } \\
\text { tares às atividades de inovação da } \\
\quad \text { empresa } \\
\text { Q1.11. Projetos de PEBD substitutos às } \\
\text { atividades de inovação da empresa }\end{array}$ \\
\hline
\end{tabular}

Fonte: Elaboração própria com base no Survey Brasil.

Como dito anteriormente, cada respondente graduou cada item do Quadro 1 pela sua nota de importância que varia de 1 a 4 . Com o intuito de fazer histogramas, foi necessário transformar as respostas de forma que elas estejam alocadas entre os valores de 0 a 1 . Dessa forma, as respostas serão transformadas em 0; 0,3;

3 Além de informações sobre tipos de relacionamentos, o questionário contempla outros aspectos da interação entre grupos de pesquisa e empresas, como os principais resultados gerados, os benefícios e dificuldades da relação, os canais de informação para transferência de conhecimento e as fontes de financiamento mobilizadas. 
0,6; e 1. Além desse processo, cada um dos dois indicadores também terá um valor compreendido entre o intervalo de 0 e 1 e essa operação será feita a partir de uma média simples dos resultados dos itens que compõem o indicador para cada grupo em específico. Os histogramas são utilizados para observarmos a distribuição dos indicadores construídos. O software utilizado para esse exercício foi o STATA 12 e a Figura 1 apresenta os resultados.

Figura 1 - Histogramas de distribuição dos indicadores dos tipos de interação

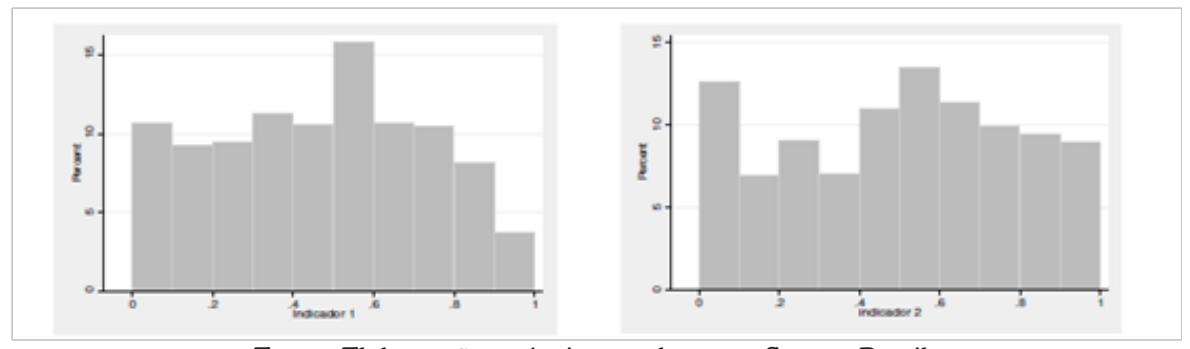

Fonte: Elaboração própria com base no Survey Brasil.

A análise de histograma se dá pela observação da distribuição das observações em cada um dos decis. Para uma distribuição totalmente homogênea cada, decil teria 10\% das observações, e quanto mais distantes disso, mais heterogêneos são os dados. Nos indicadores aqui gerados, nota-se uma concentração mais homogênea da importância dada pelos grupos de pesquisa. No indicador 1, prestação de serviços, os intervalos de escores de 0 a 0,5 se mantiveram muito próximos aos $10 \%$. A maior concentração se dá no intervalo entre 0,5 e 0,6, que apresenta valor superior a $15 \%$. Os valores do intervalo de 0,6 a 0,8 são similares àqueles menores que 0,5. Entretanto, os posicionados nos decis mais elevados apresentam as menores concentrações. A média dessa medida é 0,46 e o desvio o padrão de 0,26 . O indicador $2, P \mathcal{E}$, também apresenta uma distribuição bastante simétrica. Entretanto, devem-se ressaltar algumas diferenças, como a concentração de grupos de pesquisa com valores menores que 0,1 acima de 10\%. Assim, como no indicador 1, a maior concentração se dá entre 0,5 e 0,6, ou seja, um maior número de grupos que dão avaliação média para essa dimensão. Porém, existe um número maior de grupos concentrados no último decil, com aproximadamente 10\%. A média foi de 0,47 e o desvio padrão de 0,3. Esses resultados demonstram que os indicadores têm distribuições similares e pode-se concluir que existem grupos que identificam os relacionamentos de forma distinta. Porém, apenas com essa análise simples não se pode dizer que grupo - ou grupos - de uma determinada área dão notas melhores ou piores para cada relacionamento. A comparação da importância que determinada área de conhecimento dá para cada indicador será realizada adiante neste trabalho, a partir da utilização de técnicas estatísticas descritas na próxima seção. 
A seguir será discutida a metodologia da análise multivariada a partir do método de componente principal. Entretanto, cabe ressaltar ainda nessa seção que o fato de os dados se apresentarem homogeneamente distribuídos corrobora com a análise seguinte. Como tal método se dá por médias e correlações, os componentes poderiam estar viesados em regiões nas quais os dados estivessem desproporcionalmente concentrados.

\section{Metodologia da Análise Multivariada}

A técnica utilizada no trabalho compreende três passos. Inicialmente, realiza-se a análise de componente principal dos tipos de relacionamento. O objetivo desse exercício consiste tanto em uma redução da dimensionalidade dos dados e na obtenção de combinações interpretáveis de variáveis com o intuito de criação de indicadores. (BARROSO; ARTES, 2003). Assim, supõe-se que exista (p) variáveis em uma base de dados e se buscará construir um modelo com (r) variáveis, desde que $r<p$. Cada variável $r$ será interpretada como um indicador representativo das variáveis p agrupadas. De acordo com Mingoti (2005), o método pode ser descrito a partir de um vetor $\mathrm{X}$ de variáveis aleatórias pela equação 1 :

$$
X=\left[x_{1}, x_{2}, x_{3}, \ldots, x_{p},\right]
$$

Sendo que p representa o número de variáveis aleatórias e $\mathrm{X}$ tem a matriz de variância e covariância representada por $\sum$, como na equação 2:

$$
\operatorname{var} / \operatorname{covar}(X)=\sum{ }_{p x p}
$$

Os componentes se dão a partir de uma decomposição da matriz de variância e covariância por vetores (e) de autovalores. Os vetores têm o mesmo número de linhas que variáveis. Assim, pode-se construir componentes com base nesses vetores a partir de combinações lineares que são escritos pela equação 3:

$$
Y_{i}=e_{i 1} x_{1}+e_{i 2} x_{2}+e i 3 x_{3}+\ldots+e_{i p} x_{p}
$$

Em que:

$\mathrm{Y}_{\mathrm{i}}$ é a iésima componente

$\mathrm{e}_{\mathrm{i}}$ é o peso ou coeficiente da iésima componente dado pelo autovetor p é o número de variáveis representadas pela componente.

Cada vetor $\mathrm{X}$ terá $\mathrm{p}$ componentes. Essas são ordenadas de forma que a primeira componente representa a maior variância possível, a segunda componente 
captura o máximo da variância restante e assim sucessivamente (MINGOTI, 2005). Para que isso seja possível, realiza-se uma maximização lagrangeana na equação 4 em que:

$$
\begin{aligned}
& \text { Max } \operatorname{Var}\left(Y_{\mathrm{i}}\right)=\mathrm{e}_{\mathrm{i}}^{\prime} \sum \mathrm{e}_{\mathrm{i}} \\
& \text { s. a. } \quad \mathrm{e}_{\mathrm{i}}^{\prime} \mathrm{e}_{\mathrm{i}}=1 \text { (o vetor é unitário) } \\
& \mathrm{e}_{\mathrm{i}}^{\prime} \mathrm{e}_{\mathrm{k}}=0 \text { (ortogonalidade dos vetores) }
\end{aligned}
$$

Sendo $k$ um vetor diferente do vetor $i$.

O número de componentes escolhidos foi aquele que explicava pelo menos $70 \%$ da base, sendo encontrados 4 indicadores para os tipos de relacionamento. Após a estimação do modelo, foi escolhido um método de rotação varimax normalizado para garantir ortogonalidade das componentes geradas. Isso faz com que as componentes geradas tenham uma distribuição normal e estejam correlacionadas entre si. (MINGOTI, 2005)

O segundo passo consiste na separação dos grupos de pesquisas em clusters a partir de um método de agrupamento das componentes principais. Assim, os valores são agrupados de acordo com algum critério de similaridade. No presente caso, foi escolhida a distância euclidiana por dar pesos iguais para cada um dos indicadores. Essa pode ser representada pela fórmula da equação 5:

$$
\mathrm{d}_{\mathrm{ik}}=\sqrt{\sum_{\mathrm{j}=1}^{\mathrm{p}}\left(\mathrm{x}_{\mathrm{ij}}-\mathrm{x}_{\mathrm{ik}}\right)^{2}}
$$

Sendo que $x_{i}$ é o vetor das $i$ variáveis inserido no modelo de aglomeração. Nesse caso, as variáveis são representadas pelos componentes anteriormente gerados. O número de clusters é arbitrário e a partir da sua escolha são definidos pontos (sementes) que minimizam o somatório das distâncias das observações (MINGOTI, 2005). Aqui foi escolhido o menor número de clusters possíveis em que a variância das componentes de cada um fosse menor que um. Isso ocorre pelo fato de que na base geral, a variância é um dos motivos das variáveis terem uma distribuição normal. Assim, realiza-se o cálculo da distância de cada observação para cada uma das sementes escolhidas e a observação é alocada no grupo em que a distância for menor. O software utilizado nessas duas primeiras etapas foi o Statistica 12.0.

O terceiro e último passo consiste em analisar a participação de cada área do conhecimento em cada um dos clusters. Isso se tornou necessário pelo fato de as áreas do conhecimento estarem muito dispersas dentre os clusters, dificultando a análise de forma bruta. No procedimento utilizou-se um indicador de participação 
(quociente de participação - QP) derivado do quociente locacional. Esse indicador pode ser representado pela equação 6:

$$
Q P_{i j}=\frac{\frac{X_{i j}}{y_{j}}}{/ \frac{\sum_{i} X_{i}}{\sum_{j} Y_{j}}}
$$

Em que:

$Q P_{i j}=$ quociente de participação dos grupos da área i no cluster j

$\sum x_{i}$ número de grupos da área do conhecimento $i$ no cluster $j$

$\sum_{i}^{t} r_{j}$ total de grupos alocados no cluster $j$

$\sum_{j}=$ total de grupos da área de conhecimento $i$

$=$ total de grupos

A interpretação da equação 6 poderá assumir valores em quatro níveis. Caso seja maior que 1, pode-se dizer que a determinada área do conhecimento está concentrada no cluster em número de observações. Se o valor for menor que 1 , o cluster não concentrará os grupos de pesquisa de determinada área do conhecimento. Caso seja exatamente 1 , tanto a representatividade no cluster quanto na base como um todo são idênticas. No caso do resultado da equação ser zero, significa que não existem grupos de pesquisa de determinada área localizados no cluster. Quanto mais distante for o valor dessa equação, maior é a concentração dos grupos de determinada área no cluster.

\section{Tipos de Interação Universidade-Indústria: Análise de Resultados}

A questão retirada do questionário contemplava 11 itens para os diversos tipos de relacionamento para que os entrevistados avaliassem conforme o descrito nas seções 3 e 4 desse trabalho. Entretanto, por motivos de ajuste, apenas 9 itens foram utilizados na criação de 4 componentes principais. ${ }^{4}$ As componentes geradas explicam $71,74 \%$ da variância total das variáveis selecionadas, e podem ser representados pelas seguintes equações:

Componente $1=-0,083$ Q1 1-1-0,084 Q1 -2-0,055 Q1 3-0,113 Q1 -4-0,046 Q1 .5+0,309 Q1.8+0,390 Q1.9+0,368 Q1.10+0,317 Q1.11

4 As questões 1.6 (Intercâmbio nas empresas) e 1.7 (Transferência de tecnologia e licenciamento) foram retiradas da análise fatorial por não ser possível alocá-las em nenhum dos fatores. Isso ocorre por elas estarem fortemente correlacionadas com mais de uma componente e ser impossível definir em qual delas ficaria mais forte. 
Componente $2=-0,140$ Q1.1-0,022 Q1.2-0,157 Q1.3+0,557 Q1.4+0,786 Q1.50,067 Q1.8+0,030 Q1.9-0,075 Q1.10-0,122 Q1.11

Componente 3=0,800 Q1.1-0,452 Q1.2-0,131 Q1.3+0,172 Q1.4+0,064 Q1.50,021 Q1.8-0,205 Q1.9-0,044 Q1.10+0,103 Q1.11

Componente $4=-0,237 \mathrm{Q} 1.1+0,152 \mathrm{Q} 1.2+0,912 \mathrm{Q} 1.3+0,242$ Q1.4-0,319 Q1.5+0,028 Q1.8-0,145 Q1.9-0,002 Q1.10-0,015 Q1.11

A componente 1 representa projetos de PẺD em colaboração com a empresa com resultados de uso imediato (Q1.8), projetos de PED em colaboração com a empresa sem resultados de uso imediato (Q1.9), projetos de PED complementares às atividades de inovação da empresa (Q1.10) e projetos de PED substitutos às atividades de inovação da empresa (Q1.11). Isso demonstra que essas categorias são correlacionadas, apesar de terem características distintas. Como demonstram Suzigan et al. (2011), os projetos de PEBD em colaboração com a empresa com resultados de uso imediato são marcados por interações com tempo determinado e descontínuas. Por outro lado, os projetos de PEDD em colaboração com empresas sem uso imediato representam interações contínuas em que os parceiros buscam se conhecer o máximo possível para que possam proteger os resultados gerados. Esse tipo é marcado por geração de conhecimento novo para o mercado ou mesmo para um país como todo. Apesar das diferenças, os itens foram avaliados com notas semelhantes pelos grupos de pesquisa. Essa componente será entendida como um indicador para as interações em projetos compartilhados de pesquisa e desenvolvimento.

O segundo componente explica a variância de consultorias (Q1. 4) e treinamento e curso (Q1. 5). Assim como no caso do primeiro componente, é possível notar diferenças entre os dois itens. As consultorias não marcam trocas diretas de conhecimento, mesmo que a partir delas possam surgir projetos de pesquisa mais bem elaborados, e são apenas a solução ou identificação de problemas de uma empresa a partir de conhecimento já desenvolvido. Já os treinamentos e cursos abarcam desde a participação em cursos até a produção de trabalhos acadêmicos. Essa pode ser uma boa maneira de se transferir conhecimento das universidades e uma porta para a admissão de mão de obra capacitada (SUZIGAN et al., 2011). Esse componente é um bom indicador para as interações tradicionais, como foram chamados no trabalho de Arocena e Sutz (2003), para caracterizar a interação universidade-empresa na América Latina.

O terceiro componente capta a maior variação dos testes para padronização/ atividades de certificação de qualidade (Q1.1) e avaliações técnicas, estudos de viabilidades e gerenciamento de projetos (Q1.2). Ambos os itens relacionam-se 
com a utilização da infraestrutura universitária por parte das empresas, sem que ocorra o desenvolvimento de novos conhecimentos ou mesmo a troca sistemática de conhecimentos já existentes. Desse modo, esse componente representa um indicador que evidencia a utilização da infraestrutura universitária para a realização de testes e avaliações de interesse das empresas.

Por fim, o quarto componente representa os serviços de engenharia (Q1.3). Suzigan et al. (2011) consideram que esse tipo de interação é marcado por não estabelecer uma atividade rotineira apesar de se observar trocas duplas de conhecimento. Se essa relação contemplar fluxos bidirecionais de conhecimento, podendo inclusive envolver a produção de equipamentos para um fim específico de um grupo de pesquisa, torna-se necessário um trabalho de aprendizado entre os agentes.

Cada observação (grupo de pesquisa) apresenta um valor, denominado escore, para cada uma das equações acima. Em seguida, foram realizados agrupamentos em clusters com o objetivo de encontrar similaridades entre os grupos de pesquisa. Para tanto, escolheu-se o método das k-médias, que determina pontos médios, ou seja, sementes, dos quais se calcula a distância para todas as observações. As observações com menores distâncias perante a determinada semente pertencerão ao cluster formado no entorno dela. No caso da questão em estudo, cinco clusters serão formados com base nas quatro componentes consideradas. Os clusters identificados têm suas sementes representadas na Tabela 2 .

Tabela 2 - Clusters referentes aos tipos de relacionamentos

\begin{tabular}{|c|c|c|c|c|c|c|c|c|c|c|}
\hline Componentes/Clusters & Cluster 1 & $\begin{array}{c}\text { Desvio } \\
\text { padrão }\end{array}$ & Cluster 2 & $\begin{array}{c}\text { Desvio } \\
\text { padrão }\end{array}$ & Cluster 3 & $\begin{array}{c}\text { Desvio } \\
\text { padrão }\end{array}$ & Cluster 4 & $\begin{array}{l}\text { Desvio } \\
\text { padrão }\end{array}$ & Cluster 5 & $\begin{array}{c}\text { Desvio } \\
\text { padrão }\end{array}$ \\
\hline 1-Projetos compartilhados de P\&D & $-0,246$ & 0,979 & 0,468 & 0,694 & $-1,193$ & 0,506 & 0,786 & 0,596 & $-0,031$ & 0,893 \\
\hline 2- Interaçбes tradicionais & $-1,294$ & 0,519 & 0,158 & 0,749 & 0,609 & 0,744 & 0,590 & 0,696 & 0,112 & 0,847 \\
\hline 3- Testes e avaliações & $-0,411$ & 0,662 & 1,181 & 0,457 & $-0,114$ & 0,847 & $-0,907$ & 0,601 & $-0,093$ & 0,844 \\
\hline 4-Serviços de engenharia & $-0,387$ & 0,476 & $-0,177$ & 0,806 & $-0,514$ & 0,605 & $-0,485$ & 0,635 & 1,597 & 0,501 \\
\hline Número de grupos & 187 & & 219 & & 151 & & 164 & & 168 & \\
\hline
\end{tabular}

Fonte: Elaboração própria com base em dados do Survey Brasil.

A Figura 2, por sua vez, ajuda a visualizar o posicionamento das sementes por um gráfico radar. O desvio padrão nos serve para entender a cobertura que determinado cluster tem, ou seja, é um indicador da distância do centro a borda. A Tabela 3 traz a classificação dos clusters perante cada área do conhecimento seguido do cálculo do coeficiente de participação. 
Figura 2 - Tipos de relacionamento

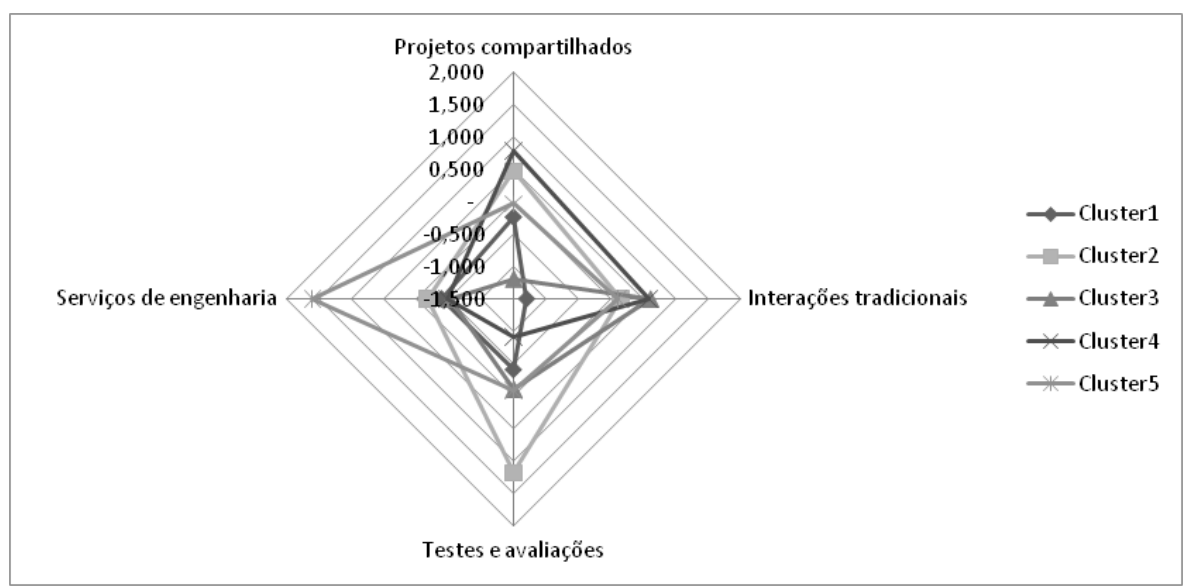

Fonte: Elaboração própria com base em dados do Survey Brasil.

Foi realizado um teste $\mathrm{F}$ para que se garantisse que as médias das variáveis fossem diferentes para cada um dos clusters. O resultado encontrado foi de P-valor próximo de zero para todas as variáveis, o que contribui favoravelmente para o ajuste da partição €.

O cluster 1 consiste de 187 grupos de pesquisas e é caracterizado por valores negativos para todas as quatro componentes. Porém, no caso de projetos compartilhados de PED, o valor em módulo é bastante pequeno e o desvio padrão é grande, aproximando-se da média. As interações tradicionais apresentam valores particularmente baixos, e pode-se constatar que os grupos aqui presentes deram pouco valor relativo a essas características. O cluster 2 tem 219 grupos e atribuiu grande valor para testes e avaliações, indicando que esses grupos deram mais importância para esses aspectos. Interações tradicionais e serviços de engenharia estão bem próximos da média e projetos compartilhados de P\&D estão relativamente altos. O cluster 3 é composto de 151 grupos de pesquisa e se caracteriza por destacar as interações tradicionais. O valor para testes e avaliações está um pouco abaixo da média e as outras duas componentes têm valores negativos significativos. No cluster 4 foram alocados 164 grupos que deram altos valores para projetos compartilhados de PEBD e interações tradicionais. Entretanto, nesse caso foram observados baixos valores para testes e avaliações e serviços de engenharia. Por fim, o cluster 5 tem 168 grupos de pesquisa com altos valores para serviços de engenharia e pertos da média para as outras componentes.

A Tabela 3 apresenta resultados bastante interessantes, demonstrando como os tipos de interação são heterogêneos no Brasil, assim como encontrado por Rapini et al. (2013) e contrapondo-se à análise de Arocena e Sutz (2003). No geral, as 
evidências apontam que as empresas procuram as universidades para projetos de pesquisa de curto prazo de natureza aplicada. Esse ponto ainda corrobora a literatura na qual diz que as empresas buscam as universidades para completar projetos já existentes (FRANCO et al., 2010). Isso ainda corrobora, em certa medida, a tese de Arocena e Sultz (2003), na qual o PEBD da firma está sendo externalizado para as universidades, aproveitando conhecimento existente sem incentivar novas pesquisas. Esse tipo de interação se caracteriza por uma pequena duração de tempo e troca de produção de conhecimento intenso e mútuo. Além dessas evidências gerais, as informações levantadas possibilitam identificar particularidades do padrão de relacionamentos nas grandes áreas de conhecimento, que evidenciam aspectos importantes do sistema nacional de inovação brasileiro. 


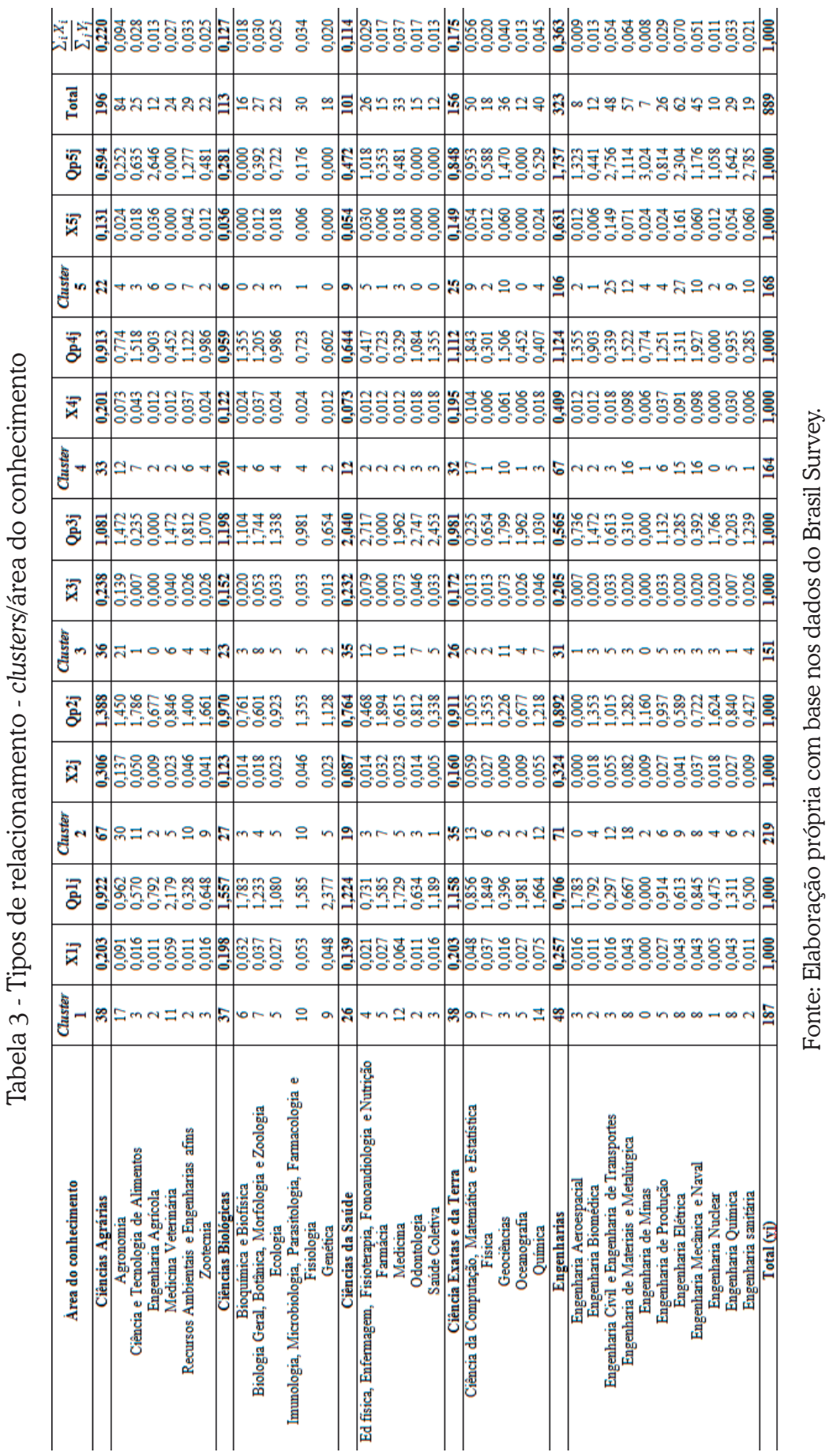


Os grupos de pesquisa de ciências agrárias concentraram-se nos clusters $2 \mathrm{e}$ 3. O primeiro desses destaca-se por atribuir maior relevância às interações de testes e avaliações e a projetos compartilhados de PEDD, enquanto o segundo considera mais relevante as interações tradicionais, atribuindo escores baixos a projetos compartilhados de PEDD. Esses resultados demonstram que a grande área é bastante heterogênea. No cluster 1, em que todos os tipos de interação são avaliados abaixo da média, nota-se a presença significativa de grupos de Medicina Veterinária. Agronomia e zootecnia se concentram nos clusters 2 e 3. Ciência e tecnologia de alimentos e recursos ambientais e engenharias afins se concentram nos clusters 2 e 4, enquanto a Medicina Veterinária também se concentra no cluster 4. A concentração no cluster 5 , que se caracteriza pela ênfase em serviços em engenharia, apresenta-se baixa para o conjunto da grande área, de apenas 0,594. Porém, os campos de Engenharia Agrícola e recursos ambientais e engenharias afins se encontram concentrados nesse último cluster.

As ciências biológicas se concentram nos clusters 1 e 3, sendo que a participação no cluster 5 é muito baixa. O primeiro desses se caracteriza por ter uma semente com valores de importância negativos para todas as componentes, enquanto o segundo tem valor positivo apenas para os tipos de interação tradicionais. Considerando as diversas áreas de conhecimento, verifica-se que esse mesmo resultado é encontrado para a área de ecologia. Os campos de bioquímica e biofísica e biologia geral, botânica, morfologia e zoologia se concentram nos clusters 1, 3 e 4. Já as áreas de imunologia, microbiologia, parasitologia, farmacologia e fisiologia têm maior participação nos clusters 1 e 2. Por fim, é interessante observar como a área do conhecimento genética apresenta muitos grupos no cluster 1, em que as interações no geral são avaliadas com baixos escores.

As ciências da saúde têm um padrão similar às ciências biológicas, concentrando-se nos clusters 1 e 3 . Entretanto, elas têm um peso muito maior no cluster 3, o que é explicado pelo forte peso de treinamentos e cursos nas ciências que as compõem. Esse padrão é observado nas áreas de conhecimento de Educação Física, Enfermagem, Fisioterapia, Fonoaudiologia e Nutrição, que aparecem concentradas no cluster 3. A área de Farmácia está concentrada nos clusters 1 e 2, sendo que o segundo cluster demonstra bem o padrão de articulação dessa área com o setor produtivo no Brasil, contemplando tanto testes de validação dos medicamentos quanto com alguns desenvolvimentos de pesquisas conjuntas. A área de medicina concentra-se nos clusters 1 e 3, assim como as ciências da saúde em geral. Já Odontologia aparece nos clusters 3 e 4 e saúde coletiva nos clusters 1, 3 e 4 .

Para as ciências exatas e da terra, observa uma concentração nos clusters 1 e 4. Essa grande área se apresenta muito heterogênea pelo caráter das ciências aí localizadas. As áreas de Ciência da Computação, Matemática e Estatística aparecem nos clusters 2 e 4, sendo mais forte no cluster 4 , enquanto que a área de 
Física tem quocientes de participação maiores que 1 para os clusters 1 e 2. A área de geociência concentra-se nos clusters 3, 4 e 5, e Oceanografia nos clusters 1 e 3. Por fim, nota-se que Química se localiza nos clusters 1, 2, 3. Enquanto Ciência da Computação, Matemática e probabilidade avaliam as atividades de PESD com notas mais altas, outras áreas, como Física e Química, se concentram mais em relacionamentos tradicionais.

As engenharias estão concentradas nos clusters 4 e 5, como já se era de esperar, caracterizando-se como a única grande área que avalia as atividades de serviço de engenharia com notas acima da média. Essa grande área é a que apresenta um maior número de ciências, no caso aqui representado pela gama de engenharias existentes, além de ser aquela mais heterogênea para essa questão. Os grupos de ciência aeroespacial estão concentrados nos clusters 1, 4 e 5. Entretanto, assim como ocorre com Engenharia de Minas, existem poucas observações para essas ciências. O campo de Engenharia Biomédica está mais próximo das ciências biológicas e ciências da saúde, se concentrando nos clusters 2 e 3. A Engenharia Civil, Engenharia de Transportes e Engenharia de Minas se concentram nos clusters 2 e 5. Para Engenharia de Materiais e Metalúrgica, a concentração se dá nos clusters 2, 4 e 5. Outra área que se comporta de forma um pouco diferente é a Engenharia de Produção, que se concentra nos clusters 3 e 4. Entretanto, observa-se que essa tem uma distribuição mais homogênea dentre as categorias. A Engenharia Elétrica e a Engenharia Mecânica e Naval concentram-se nos clusters 4 e 5, e a Engenharia Nuclear nos clusters 2, 3 e 5. Por fim, nota-se que a Engenharia Química se concentra nos clusters 1 e 5 e a Engenharia Sanitária nos clusters 3 e 5.

\section{Considerações Finais}

A análise realizada demonstra que os tipos de interação são muito diversos para os grupos de pesquisa do Brasil e variam de acordo com a área de conhecimento na qual ele está inserido. É fácil perceber que existem grupos em certas áreas, como Medicina e Medicina Veterinária, que valorizam todas as interações com notas abaixo da média geral. Entretanto, em outros casos, como em alguns campos da ciência da saúde, há notas elevadas atribuídas a interações que dizem respeito aos treinamentos e cursos (que podem ser caracterizados como interações tradicionais). Isso pode ser explicado pelo caráter de transmissão de conhecimento desses campos que dificilmente têm produção industrial ou cuja produção científica raramente se converte em patentes. Existem também grupos de determinadas áreas que identificaram os projetos compartilhados de PẺD como interação importante, o que pode ser visto pelos quocientes de participação de Ciências da Computação, Matemática e Estatística e Engenharia Mecânica e Naval. 
Sobre os componentes gerados, observa-se que o primeiro deles aponta para uma forte correlação existente entre atividades conjuntas de P\&BD orientadas para o desenvolvimento de problemas pontuais e para problemas de longo prazo. A relevância desse componente reflete situações nas quais os pesquisadores avaliam que a universidade brasileira não está apenas vinculada a soluções de atividades descontínuas e que substituem a pesquisa de adaptação de produtos, mas também está responsável por gerar novos conhecimentos. Na avaliação realizada, ambos os tipos de interação são avaliados com altos valores por grupos de pesquisa semelhantes. O segundo componente demonstra que existe uma correlação entre a importância atribuída a diversos tipos de interações tradicionais vinculadas à prestação de serviços. A ênfase em testes e avaliações pode apontar para situações nas quais os departamentos das universidades são utilizados como departamentos das próprias empresas, substituindo esforços inovativos in-house, o que encontra embasamento na literatura relacionada ao tema. Essa configuração faz com que o processo de inovação seja descontínuo e localizado em determinados problemas como captado por esse indicador. O mesmo ocorre no caso de serviços de engenharia, mas nesse caso, apesar da troca de conhecimento não constituir uma atividade rotineira, a mesma pode ocorrer em função do objeto da interação, o que estimularia processos de aprendizado mútuo entre os agentes, com potencial de incrementar as respectivas capacitações inovativas.

O trabalho demonstrou que a tese defendida em Arocena e Sutz (2003), segundo a qual a interação entre universidade e empresa na economia latino-americana estaria calcada em relações tradicionais, não pode ser totalmente sustentada para o Brasil. Apesar desse tipo de interação ser muito forte em áreas do conhecimento, como aquelas ligadas à saúde, o mesmo não pode ser dito para outras áreas que atribuem maior relevância às atividades de PEBD. Além do mais, não pode ser negado o papel de 'antena' do conhecimento mundial desempenhado pelas universidades brasileiras, conforme discutido por Rapini (2007). Os grupos de pesquisa brasileiros, assim como na periferia em geral, teriam um papel adicional ligado à absorção e propagação de conhecimento desenvolvido nos grandes centros da economia mundial. Isso ocorreria pelo fato da limitada existência de departamentos de PED nas empresas privadas, que acabam por utilizar a estrutura de pesquisa das universidades em atividades rotineiras. Por esse último argumento, pode-se entender que mesmo atividades tradicionais, como consultorias, por exemplo, têm um papel diferenciado em países periféricos como o Brasil.

Apesar das dificuldades de estabelecer rotinas mais sistemáticas de interação entre universidades e empresas em um país caracterizado por um sistema de inovação "imaturo", o governo brasileiro vem realizando alguns esforços nessa direção. Isso pode ser visto na lei dos fundos setoriais e na estruturação do programa Ciências Sem Fronteiras. O primeiro desses exige que empresas em alguns 
setores da economia invistam parte de suas receitas em atividades universitária para terem incentivos fiscais. Esses recursos permitem que grupos de pesquisa de instituições públicas, principalmente em regiões menos desenvolvidas, possam manter laboratórios de alto nível tecnológico. Assim, pode-se absorver com certa velocidade o conhecimento de fronteira. $\mathrm{O}$ segundo programa visa aumentar o intercâmbio de estudantes brasileiros em universidades exteriores, tanto em nível de graduação como em nível de pós-graduação. Essa ação visa reduzir a defasagem de capital humano em várias áreas de pesquisa e mesmo no setor produtivo nacional. Entretanto, esses programas ainda são bastante recentes e ainda não permitiram que o país superasse sua característica imatura no que diz respeito à inovação. Esse último ponto pode ser visto no baixo número de patentes em relação ao número de artigos, como expressado no trabalho de Bernardes e Albuquerque (2003). Mais recentemente, essas ações têm procurado também avançar na indução de demandas tecnológicas pelo setor empresarial, através da concessão de financiamentos no âmbito do programa Inova Empresa e da estruturação do sistema Sibratec-Embrapii como meio para o atendimento dessas demandas de forma mais ágil e efetiva.

É importante ressaltar também a diversidade de padrões que orienta a interação universidade-empresa no caso brasileiro, refletindo não apenas a usual heterogeneidade da estrutura produtiva nacional, mas também a heterogeneidade das competências acumuladas em diferentes campos científicos. Nesse sentido, é natural que a aproximação entre essas duas instâncias no sentido da viabilização de processos mais sistemáticos de interação ocorra através de múltiplas vias. As evidências apresentadas corroboram a descrição de experiências realizada por Suzigan e Albuquerque (2008), que englobam tanto experiências nas quais centros de pesquisa científica geram conhecimentos que são incorporados indistintamente por agentes econômicos privados como casos onde se forma uma conexão mais direta entre empresas e centros de pesquisa. Do ponto de vista das universidades, as motivações para essas interações, que se referem tanto a motivações intelectuais como a motivações econômicas, devem considerar as contribuições que os avanços científicos dão para a produção no curto prazo e para a inovação no longo prazo (DUTRÉNIT; ARZA, 2010). Destaca-se também a relevância da mobilidade de recursos humanos entre universidades e firmas como fator de estímulo à transmissão de conhecimento (BEKKERS; BODAS-FREITAS, 2008). No caso latino-americano, em função do baixo nível de PËD interno realizado pelas empresas locais, há controvérsias quanto à possibilidade das articulações universidade-empresa ficarem circunscritas à prestação de serviços rotineiros e a atividades de consultoria técnica, raramente envolvendo atividades de pesquisa de caráter mais experimental (DUTRÉNIT; ARZA, 2010). No entanto, as evidências levantadas apontam na direção de padrões de interação mais complexos e multi- 
facetados, convivendo situações nas quais esse padrão se combina com situações pontuais em que as universidades e instituições de pesquisa procuram compatibilizar a geração de avanços que tenham uma relevância direta para a sociedade com pesquisas mais densas, na linha apontada por Rapini et al. (2013).

Nesse sentido, o avanço no estudo da interação universidade-empresa constitui um campo bastante promissor. A tentativa de compreender as peculiaridades das áreas de conhecimento é importante para aplicar políticas econômicas que busquem fomentar diferentes tipos de relacionamentos. A discussão sobre os padrões de articulação das universidades com o setor produtivo nos diferentes campos científicos deve também ser articulada a outros elementos que conferem um maior ou menor dinamismo aos sistemas de inovação, não apenas no nível nacional, como também nas escalas regionais e locais. As evidências levantadas também indicam que há um potencial expressivo de transferência de conhecimentos em áreas científicas de natureza mais aplicada, o que pode operar como fator de dinamização do sistema nacional de inovação, na presença de um manejo adequado de estímulos de política. Por fim, cabe dizer que pesquisas como a utilizada no trabalho deveriam ser realizadas com uma periodicidade definida com o intuito de avaliar a evolução do processo no Brasil.

\section{Referências}

ALBUQUERQUE, E. National systems of innovation and non-OECD countries: notes about a tentative typology. Revista de Economia Política, v. 19, n. 4, p. 35-52, 1999.

AROCENA, R.; SUTZ, J. Knowledge, innovation and learning: systems and policies in the north and in the south. In: CASSIOLATO, J.; LASTRES, H.; MACIEL, M. (Ed.). Systems of Innovation and Development: evidence from Brazil. Rio de Janeiro: Edward Elgar, 2003.

ARVANITS, S. et al. University-industry knowledge and technology transfer in Switzerland: what university scientists think about co-operation with private enterprises. Resarch Police, v. 37, n. 10, p. 1865-1863, 2008.

ARZA, V. Chanel, benefits and risks of public-private interaction for knowledge transfer: a conceptual framework inspired by Latin America. Science and Public Police, v. 37, n. 7, p. 499-511, 2010.

BARROSO, L.; ARTES, R. Análise multivariada. Lavras: Departamento de Ciências Exatas, UFLA, 2003.

BEKKERS, R.; BODAS-FREITAS, I. Analyzing knowledge transfer channels between universities and industry: To what degree do sectors also matter? Research Police, v. 37, n. 10, p.1838-1553, 2008.

BERNARDES, A.; ALBUQUERQUE, E. Cross-over, thresholds, and interactions between science and technology: lessons for less-developed countries, Research Police, v. 32, n. 5, p. 865-885, 2003. 
BOARDMAN, P.; PONOMARIOV, B. University researchers working with private companies. Technovation, v. 29, p. 142-153, 2009.

BRANSCOMB, L. et al. Industrial knowledge: university-industry linkages in Japan and the United State. Cambridge, MA: The MIT Press, 1999.

BRITTO, J.; OLIVEIRA, B. Padrões setoriais de interação universidade-empresa no Brasil: um mapeamento de competências a partir de informações da pesquisa "Brazil Survey". Revista de Economia, v. 37, n. 3, p. 167-212, 2011.

COHEN, W. et al. Links and impacts: the influence of public RED on industrial research. Management Science, v. 48, n. 1, p. 1-23, 2002.

COOKE. F. et al. Regional systems of innovation: an evolutionary perspective. Environment and Planning, v. 30, p. 1563-1584, 1998.

COSTA, A. et al. Proximidade geográfica e interação universidade-empresa no Rio de Janeiro. Revista de Economia, v. 37, n. 3, p. 213-238, 2011.

DUTRENIT, G.; ARZA, V. Channels and benefits of interactions between public research organism and industry: comparing four Latin American countries. Science and Public Police, v.37 p. 541-553, 2010.

FRANCO, L. et al. Características da interação entre universidades e institutos públicos de pesquisa (IPPs) e empresas em Minas Gerais sob a perspectiva de ambos agentes do sistema estadual de inovação: notas introdutórias. In: SEMINÁRIO DE ECONOMIA MINEIRA, 12. 2010, Diamantina. Anais... Belo Horizonte: Cedeplar, 2010.

FREEMAN, C.; SOETE, L. A economia da inovação industrial. Campinas: Editora da Unicamp, 2008.

FUENTES, C.; DUTRÉNIT, G. Best channels of academia: industry interaction for long-term benefit. Research Police, v. 41, n. 9, p. 1666-1682, 2012.

GARCIA, R. et al. Os efeitos da proximidade geográfica para o estímulo da interação universidade-empresa. Revista de Economia, v. 37, n. 3, p. 307-330, 2011.

GIBBONS, M. et al. The new production of knowledge: the dynamics of science and research in contemporary societies, London: Sage Publications, 1994.

JOHNSON, B. Cities, systems of innovation and economic development. Innovation: Management, Policy \& Practice, v. 10, n. 3, p. 146-155, 2008.

KLEVORICK, A. et al. On the sources and significance of interindustry differences in technological opportunities. Research Policy, v. 24, n. 2, p.185-205, 1995.

LASTRES, H. et al. Interagir para competir: promoção de arranjos produtivos e inovativos no Brasil. Brasília: Sebrae, 2002.

LIST, F. Sistema nacional de economia política. São Paulo: Abril Cultural, 1983. 
LUNDVALL, B. A National Innovation Systems: analytical concept and development tools. In: DRUID TENTH ANNIVERSARY SUMMER CONFERENCE, 2005, Copenhagen. Anais... Copemhagen: DRUID, 2005.

LUNDVALL, B. A. Introduction. In: LUNDVALL, B. A. National Systems of Innovation: towards a theory of innovation and interactive learning. London: Printer Publishers, 1992.

MALERBA, F. Sectoral systems of innovation and production. Research Policy, v. 31, n. 2, p. 247-264, 2002.

MAZZOLENI, R.; NELSON, R. Public research institutions and economic catch-up. Research Police, v. 36, n. 10, p. 1512-1528, 2007.

MINGOTI, S. Análise de dados através de métodos de estatística multivarida: uma análise aplicada. Belo Horizonte: Editora da UFMG, 2005.

MOWERY, D. et al. Ivory tower and industrial innovation: university-industry technology transfer before and after the Bayh-Dole Act. Stanford: Stanford University, 2004.

NARIN, F. et al. The increasing linkage between U.S. technology and public science. Research Policy, v. 26, n. 3, p. 317-330, 1997.

NELSON, R. National Innovation Systems: a comparative analysis. New York: Oxford University, 1993.

PERKMANN, M.; WALSH, K., Engaging the scholar: three types of academic consulting and their impact on university and industry. Research Policy, v. 37, n. 10, p. 1884-1891, 2008.

PINHO, M., A visão das empresas sobre a relação entre universidade e empresas no Brasil: Uma análise baseada nas categorias de intensidade tecnológica. Revista de Economia, v. 37, n. 3, p. 279-306, 2011.

PÓVOA, L; MONSUETO, S. Tamanho das empresas, interação com as universidades e inovação. Revista de Economia, v. 37, n. 3, p. 7-21, 2011.

RAPINI, M. et al. Innovation system and development in Latin America: university-industry interactions in Brazil. In: ENCONTRO NACIONAL DE ECONOMIA POLÍTICA, 18., 2013, Belo Horizonte. Anais... São Paulo: SEP, 2013.

RAPINI, M. Interação universidade-indústria no Brasil: uma análise exploratória a partir do diretório de pesquisas do CNPq. 2004. Dissertação (Mestrado em Economia) - Instituto de Economia, Universidade Federal do Rio de Janeiro, Rio de Janeiro, 2004.

RAPINI, M. S. Interação universidade-empresa no Brasil: evidências do diretório dos grupos de pesquisa do CNPq. Estudos Econômicos, São Paulo, v. 37, n. 1, p. 211-233, 2007.

ROSENBERG, N. Inside the balck box: technology and economics. Cambridge: Cambridge University, 1982

SCHARTINGER, D. et al. Interactive relations between universities and firms: empirical evidence for Austria. Journal of Technology Transfer, v. 26, n. 3, p. 255-268, 2001. 
SCHARTINGER, D. et al. Knowledge interactions between universities and industry in Austria: sectorial patterns and determinants. Research Police, v. 31, n. 3, p.303-328, 2002.

SILVA NETO, F. et al. A interação universidade/instituto público de pesquisa e empresa no Brasil: resultados comparativos entre o relacionamento com empresas nacionais e multinacionais. Revista de Economia, v. 37, n. 3, p. 117-140, 2011.

SILVA, L. A. Padrões de interação entre ciência e tecnologia: uma investigação a partir de estatísticas de artigos e patentes. 2003. Dissertação (Mestrado em economia) - Centro de Desenvolvimento e Planejamento Regional, Universidade Federal de Minas Gerais, Belo Horizonte, 2003.

SUTZ, J. The university-industry-government relations in Latin America. Research Policy, v. 29, n. 2, p. 279-290, 2000.

SUZIGAN, W. et al. Em busca da inovação: interação universidade-empresa no Brasil. Belo Horizonte: Autêntica, 2011.

SUZIGAN, W.; ALBUQUERQUE, E. A interação entre universidades e empresas em perspectiva histórica no Brasil. Belo Horizonte: UFMG/Cedeplar, 2008. (Texto para discussão, n. 329).

. Interações de universidades e institutos de pesquisa com empresas no Brasil. 2009. Projeto CNPq Relatório Final.

. The underestimated role of universities for development: notes on historical roots of Brazilian system of innovation. In: WORLD ECONOMIC HISTORY CONGRESS, 15., Utrecht. Anais... Netherlands: WEHC, 2009.

TIJSSEN, R. Universities and industrially relevant science: toward mensurement models and indicators of enterpreneurial orientation. Research Police, v. 35, n. 10, p. 1569-1585, 2006.

Recebido em: 26/11/2014. Aceito em: 15/02/2016. 